\title{
Decomposing market orientation and its relationship to innovativeness of SMEs in Malaysia: the moderating effects of market turbulence
}

\author{
Shiaw Tong $\mathrm{Ha}^{*}$ and May Chiun Lo
}

Faculty of Economics and Business, Universiti Malaysia Sarawak, 94300 Sarawak, Malaysia Email: revetong@gmail.com Email: mclo@rimc.unimas.my *Corresponding author

\section{T. Ramayah}

School of Management, Universiti Sains Malaysia, Minden, 11800 Penang, Malaysia Email: ramayah@usm.my

\begin{abstract}
This study aims to investigate the relationship between market orientation and innovativeness, and the moderating effects of market turbulence in the context of Malaysian SMEs. Market orientation comprises three dimensional constructs, the customer orientation, competitor orientation, and interfuncional coordination. Data was gathered through self-administered questionnaires and a total of 180 respondents comprising owners and managers of small and medium sized enterprises participated in this study. Smart PLS 2.0 (M3) was employed to assess the proposed model through path modelling and bootstrapping technique. The results showed that customer orientation, competitor orientation and interfunctional coordination are positively related to innovativeness. Also, market turbulence was found to have moderated the relationship between customer orientation and innovativeness. Interestingly, the findings revealed that market turbulence negatively moderated the relationship between interfunctional coordination and innovativeness. Implications of the findings, limitations of the study and directions for future research are further discussed.
\end{abstract}

Keywords: market orientation; customer orientation; competitor orientation; interfunctional coordination; market turbulence; innovativeness; Malaysia.

Reference to this paper should be made as follows: Ha, S.T., Lo, M.C. and Ramayah, T. (2016) 'Decomposing market orientation and its relationship to innovativeness of SMEs in Malaysia: the moderating effects of market turbulence', J. International Business and Entrepreneurship Development, Vol. 9, No. 3, pp.273-290.

Biographical notes: Shiaw Tong Ha is currently pursuing his MSc specialising in Management at the Faculty of Economics and Business, Universiti Malaysia Sarawak, Malaysia. He earned his Bachelor's in Business Administration from the Universiti Malaysia Sarawak. His research interests are primarily on management, entrepreneurship, and organisational behaviour. 